\title{
Quantitative Assessment of Circulating Tumor Cells in Cerebrospinal Fluid as a Clinical Tool to Predict Survival in Leptomeningeal Metastases
}

\author{
Maria Diaz ( $\sim$ diazordm@mskcc.org ) \\ Priya Singh \\ Hunter College \\ Ivan Kotchetkov \\ Memorial Sloan Kettering Cancer Center \\ Anna Skakodub \\ Memorial Sloan Kettering Cancer Center \\ Alicia Meng \\ Memorial Sloan Kettering Cancer Center \\ Christel Tamer \\ Memorial Sloan Kettering Cancer Center \\ Robert Young \\ Memorial Sloan Kettering Cancer Center \\ Anne Reiner \\ Memorial Sloan Kettering Cancer Center \\ Katherine Panageas \\ Memorial Sloan Kettering Cancer Center \\ Lakshmi Ramanathan \\ Memorial Sloan Kettering Cancer Center \\ Elena Pentsova \\ Memorial Sloan Kettering Cancer Center
}

Memorial Sloan Kettering Cancer Center https://orcid.org/0000-0001-9103-0202

\section{Research Article}

Keywords: Leptomeningeal metastases, circulating tumor cells, biomarker, brain metastases

Posted Date: January 20th, 2022

DOI: https://doi.org/10.21203/rs.3.rs-1125467/v1

License: () (1) This work is licensed under a Creative Commons Attribution 4.0 International License. Read Full License

Version of Record: A version of this preprint was published at Journal of Neuro-Oncology on February 3rd, 2022. See the published version at https://doi.org/10.1007/s11060-022-03949-1. 


\section{Abstract \\ Purpose}

Circulating tumor cells (CTC) in cerebrospinal fluid (CSF) are a quantitative diagnostic tool for leptomeningeal metastases (LM) from solid tumors, but their prognostic significance is unclear. Our objective was to evaluate CSF-CTC quantification in predicting outcomes in LM.

\section{Methods}

This is a single institution retrospective study of patients with solid tumors who underwent CSF-CTC quantification using the CellSearch ${ }^{\circledR}$ platform between 04/2016-06/2019. Information on neuroaxis imaging, CSF results, and survival was collected. LM was diagnosed by MRI and/or CSF cytology. Survival analyses were performed using multivariable Cox proportional hazards modeling, and CSF-CTC splits associated with survival were identified through recursive partitioning analysis.

\section{Results}

Out of 290 patients with CNS metastases, we identified a cohort of 101 patients with newly diagnosed LM. In this group, CSF-CTC count (median $200 \mathrm{CTCs} / 3 \mathrm{ml}$ ) predicted survival continuously $(\mathrm{HR}=1.005,95 \% \mathrm{Cl}: 1.002-1.009, \mathrm{p}=0.0027)$, and the risk of mortality doubled ( $\mathrm{HR}=2.84,95 \% \mathrm{Cl}: 1.45-5.56, \mathrm{p}=0.0023)$ at the optimal cutoff of $\geq 61 \mathrm{CSF}-\mathrm{CTCs} / 3 \mathrm{ml}$. Neuroimaging findings of LM (assessed by 3 independent neuroradiologists) were associated with a higher CSF-CTC count (median CSF-CTCs range 1.5-4 for patients without radiographic LM vs 200 for patients with radiographic LM, $p<0.001$ ), but did not predict survival.

\section{Conclusion}

Our data shows that CSF-CTCs quantification predicts survival in newly diagnosed LM, and outperforms neuroimaging. CSF-CTC analysis can be used as a prognostic tool in patients with LM and provides quantitative assessment of disease burden in the CNS compartment.

\section{Introduction}

Leptomeningeal metastases $(\mathrm{LM})$ are a devastating complication of solid tumors, with breast and lung cancers having the highest incidence among all malignancies. LM are found in up to 5-10\% of patients with solid tumors, although autopsy studies suggest its true prevalence could be up to $30 \%[1]$. Despite treatment with intrathecal chemotherapy, available targeted therapy, immunotherapy and radiation therapy, the overall median overall survival remains less than 4 months from diagnosis[2-4]. However, some patientsparticularly those treated with novel approaches-may experience a longer survival[5], and tools to accurately guide prognostic and management conversations with LM patients are needed.

Diagnosis of LM traditionally relied on CSF cytology (presence or absence of malignant cells), which is suboptimally sensitive[6], or on magnetic resonance imaging (MRI) of the brain and spine, which has high inter-rater variability[7]. Detection and enumeration of circulating tumor cells (CTCs) in CSF has recently been used to overcome the limitations of LM diagnosis[8-14]. Specifically, the CellSearch ${ }^{\circledR}$ Circulating Tumor Cell test, which utilizes epithelial cell adhesion molecule (EpCAM)-based rare cell capture technology to immunomagnetically isolate and enumerate CTCs and detect metastatic cancer from epithelial tumors, has been validated in CSF on the CellTracks Analyzer IIß as a highly sensitive and specific platform for LM diagnosis[14]. This test is FDA approved in blood for patients with several types of metastatic carcinoma, where a correlation between CTC count and prognosis, response to treatment, and tumor burden has been shown[15-18].

A relationship between prognosis and CSF-CTC quantification at the time of initial LM diagnosis has not been well established. A study in patients with LM from lung cancer reported an increased mortality in patients with CSF-CTC numbers above an arbitrary cutoff, but the subset of patients was small (16 patients)[19]. Therefore, the purpose of this study was to evaluate the utility of CSF-CTC quantification in predicting outcomes in LM. 


\section{Methods}

This retrospective study was approved by the Memorial Sloan Kettering Cancer Center (MSKCC) Institutional Review Board. Institutional waiver of informed consent was obtained due to minimal patient risk associated with participation in the study. The MSKCC DARWIN database was used to identify patients with solid tumors who underwent CSF-CTC analysis from April 2016-when this test was approved by New York State Clinical Laboratory Improvement Amendments (CLIA)-to June 2019. Due to the nature of the test, which exclusively identifies cancer cells from tumors of epithelial origin, all patients undergoing CSF-CTC measurement had a known solid tumor diagnosis, excluding melanoma. The methods of detection of CTCs in CSF by CellSearch ${ }^{\circledR}$ technology have been described in detail in prior studies[14].

\section{Patients and Diagnostic Criteria}

Patient demographics, tumor diagnosis, date of lumbar puncture (LP) and of cancer diagnosis, date of LM diagnosis, results of MRI brain and/or spine, CSF results (including cell count, protein, glucose, cytology and CSF-CTCs), and status of systemic disease at the time of LP were collected. The diagnosis of LM was based on compatible findings in brain and/or spine MRI, results of CSF cytology, or a combination of both, as per the RANO-LM criteria[20]; date of LM diagnosis was therefore the date of the first MRI that showed radiographic signs of LM or the date of a positive/suspicious CSF cytology, whichever came first. We identified a cohort of patients with newly diagnosed LM in the period comprising the 30 days before and the 30 days after CSF-CTC collection, to reflect variability in the sequence of diagnostic tests.

\section{Neuroimaging Review by Independent Radiologists}

For all patients who had neuroimaging within 30 days of CSF-CTC analysis, three neuroradiologists independently reviewed MRI scans and scored them for presence of nodular LM, linear LM and hydrocephalus, and presence, number and size of parenchymal brain metastases, while blinded to the underlying diagnoses, the official MRI report and CSF results.

\section{Statistical Analysis}

Descriptive statistics (mean, median, and range) were used to describe variables of interest. For neuroimaging review, inter-rater agreement for three raters was calculated using Light's kappa with bootstrapped confidence intervals for categorical MRI features and the intra-class correlation coefficient (ICC) with bootstrapped confidence intervals for continuous MRI features. The ICC was characterized with a two-way random effects model of absolute agreement based on ratings by single readers. Categorical MRI features were associated with CTCs for each MRI rater using the Wilcoxon two sample test (2-category MRI feature) or the Kruskal Wallis test (3-category MRI feature). Continuous MRI features were associated with CTCs for each MRI rater using Spearman's correlation coefficient. To adjust for presence of LM prior to CSF-CTC analysis for MRI features referring to parenchymal brain metastases, generalized linear modeling was performed. Overall survival was defined from time of CSF-CTC collection until death (event) or last follow-up (censored). CSF-CTCs on a continuous scale were associated with overall survival using Cox proportional hazards modeling with hazard ratios. Recursive partitioning analysis (RPA) was used to identify CSF-CTCs splits most significantly associated with overall survival. Both univariable and multivariable Cox proportional hazards modeling were performed. MRI features by rater were also associated with overall survival using Cox proportional hazards modeling. Multivariable models adjusted for age at CSF collection, sex, number of brain metastases $(0,1-5$ or $>5)$ and systemic disease status at the CSF collection date. All tests were twosided with a level of statistical significance set at $<0.05$. All analyses were performed in SAS version 9.4 (The SAS Institute, Cary, NC) and R v3.6.0 (The R Foundation) using the 'irr' and 'boot' packages.

\section{Results}

We reviewed 290 charts of patients with CNS metastases who underwent CSF-CTC analysis, among whom 101 patients with newly diagnosed LM were identified (Figure 1A). The demographic and clinical characteristics of this cohort are described in Table 1. The median age was slightly over 60 years (range 21.9-83.3); approximately $70 \%$ of patients were female. The majority of patients had a primary lung (44\%) or breast carcinoma (35\%), reflecting the typical distributions of LM from epithelial tumors in clinical practice. 
Table 1

Demographic and clinical characteristics of patients with newly diagnosed LM $(N=101)$.

Sex

Female

$71(70 \%)$

Male

$30(30 \%)$

Age (median, range)

$60.8(21.9-83.3)$

Primary cancer diagnosis

Lung

$44(44 \%)$

EGFR-mutant

$22(22 \%)$

ALK-mutant

$3(3 \%)$

No targetable mutations

$19(19 \%)$

Breast

$35(35 \%)$

Hormone receptor positive

$19(19 \%)$

HER-2 positive

$7(7 \%)$

Triple negative

$9(9 \%)$

GI

7 (7\%)

Gynecologic

$3(3 \%)$

Head and neck

$3(3 \%)$

Bladder

$3(3 \%)$

Other $^{a}$

$6(6 \%)$

\section{Brain metastases ${ }^{b}$}

Yes

$72(71 \%)$

No

$29(29 \%)$

\section{LM diagnosed by}

CSF cytology

Neuroimaging

27 (27\%)

Neuroimaging + CSF cytology

$43(43 \%)$

\section{MRI brain with $\mathrm{LM}^{\mathrm{b}}$}

Yes

$54(53 \%)$

No

$47(47 \%)$

MRI spine with $L^{b}$

Yes

$36(36 \%)$

No

$54(53 \%)$

Not performed

$11(11 \%)$

GI: gastrointestinal, LM: leptomeningeal metastases, LP: lumbar puncture, MRI: magnetic resonance imaging. ${ }^{a}$ Includes neuroendocrine ( 2 patients), prostate (1 patient), renal (1 patient), Merkel cell (1 patient) and sarcoma (1 patient). ${ }^{b} \mathrm{Closest}$ MRI brain or spine to date of CSF-CTC analysis for that 
Sex

Reason for LP

Radiographic concern for LM

Clinical signs and symptoms
$47(47 \%)$

$15(15 \%)$

$9(9 \%)$

Headaches

$7(7 \%)$

Focal neurological deficit

$6(6 \%)$

Encephalopathy

$6(6 \%)$

Nausea/vomiting/dizziness

$5(5 \%)$

Gait instability

$4(4 \%)$

Seizures

$1(1 \%)$

Back pain

$1(1 \%)$

Visual changes

Urinary incontinence

Gl: gastrointestinal, LM: leptomeningeal metastases, LP: lumbar puncture, MRI: magnetic resonance imaging. ${ }^{a}$ Includes neuroendocrine ( 2 patients), prostate (1 patient), renal (1 patient), Merkel cell (1 patient) and sarcoma (1 patient). ${ }^{b} \mathrm{Closest}$ MRI brain or spine to date of CSF-CTC analysis for that

Twenty-nine patients (29\%) had LM only, whereas 72 patients $(71 \%)$ had both LM and parenchymal brain metastases (BrM); of these, 31 (43\%) had newly diagnosed BrM concurrent with new LM diagnosis (Figure 1B). Of the remaining 41 patients with BrM, BrM were diagnosed between 1 and 6 months prior to CSF evaluation in 15 cases (21\%), and more than 6 months prior in 26 (36\%; Figure 1 C). The diagnosis of LM was obtained through CSF cytology only in 31 patients (31\%), through MRI brain and/or spine in 27 patients (27\%) and through both modalities in 43 patients (43\%; Table 1). The median number of CSF-CTCs was 200/3ml (range 0-200+;

Supplementary table 1).

\section{CSF Circulating Tumor Cells and Overall Survival}

The median overall survival (OS) of the new LM cohort was 4.01 months $(95 \% \mathrm{CI}=2.60-6.02$ months). The number of CSF-CTCs was associated with survival in this cohort in multivariable Cox models, with higher CSF-CTC count predicting a continuous increase in mortality (adjusted hazard ratio [HR] for each additional CSF-CTC/3ml was $1.005,95 \% \mathrm{Cl}=1.002-1.009, \mathrm{p}=0.0027$; Table 2 ). On multivariable analysis, patients who had a CSF-CTC count at or above the optimal cutoff of $\geq 61 \mathrm{CSF}-\mathrm{CTCS} / 3 \mathrm{ml}$ (identified through RPA) had more than double the risk of death over the study period (median follow-up 3.9 months, range 0-27.4 months) compared with patients whose CSF-CTC count was below the cutoff (adjusted HR = 2.84, 95\% Cl = 1.45-5.56, $p=0.0023$ ). Patients with a positive/suspicious CSF cytology also had a higher risk of death (adjusted $\mathrm{HR}=2.09,95 \% \mathrm{Cl}=1.08-4.05$ ); however, this risk was smaller than the one predicted by the CSF-CTC cutoff. CSF-CTC counts also predicted survival in the subgroup of 44 patients with lung cancer (adjusted HR for each additional CSF-CTC/3ml $=1.01,95 \% \mathrm{Cl}=1.003-1.016, \mathrm{p}=0.0034$ ). For patients with CSF-CTC counts at or above the optimal cutoff for this group (identified through RPA as $\geq 23$ CSF-CTCs/3ml), risk of death was six times higher than for patients with CSF-CTC counts below the cutoff (adjusted HR $=6.48,95 \% \mathrm{Cl}=1.39-30.25, \mathrm{p}=0.02$ ). For these 44 patients, CSF cytology was also predictive of survival, again with a smaller magnitude of association (adjusted $\mathrm{HR}=5.45,95 \% \mathrm{Cl}=1.18-25.30, \mathrm{p}=0.03$ ). For patients with breast cancer $(\mathrm{N}=35)$, neither CSF-CTC count nor CSF cytology were able to predict survival (adjusted HR for CSF-CTC = $1.001,95 \% \mathrm{Cl}=0.994-1.01, \mathrm{p}=0.76$; adjusted HR for CSF cytology $=1.39,95 \% \mathrm{Cl}=0.35-5.54, \mathrm{p}=0.65)$. In the overall cohort of newly diagnosed LM, a higher CSF nucleated cell count in standard analyses as well as a lower glucose value were also associated with an increased risk of death, whereas protein count in CSF had no correlation with survival (Supplementary table 2). 
Table 2

Risk of death in LM cohorts according to CSF-CTC and cytology results.

\begin{tabular}{|c|c|c|c|c|c|c|c|c|}
\hline & \multicolumn{4}{|c|}{ All newly diagnosed LM (N=101) } & \multicolumn{4}{|c|}{ Newly diagnosed LM from lung cancer $(\mathrm{N}=44)$} \\
\hline & $\begin{array}{l}\text { Unadjusted } \\
\mathrm{HR}(95 \% \\
\mathrm{Cl})\end{array}$ & $\begin{array}{l}\text { Unadjusted } \\
\mathrm{P} \text { value }\end{array}$ & $\begin{array}{l}\text { Adjusted }^{a} \\
\text { HR }(95 \% \\
\text { Cl) }\end{array}$ & $\begin{array}{l}\text { Adjusted }{ }^{a} \\
P \text { value }\end{array}$ & $\begin{array}{l}\text { Unadjusted } \\
\mathrm{HR}(95 \% \\
\mathrm{Cl})\end{array}$ & $\begin{array}{l}\text { Unadjusted } \\
\mathrm{P} \text { value }\end{array}$ & $\begin{array}{l}\text { Adjusteda } \\
\text { HR }(95 \% \\
\text { Cl) }\end{array}$ & $\begin{array}{l}\text { Adjusted }^{\mathrm{a}} \\
\mathrm{P} \text { value }\end{array}$ \\
\hline $\begin{array}{l}\text { CSF-CTCs - } \\
\text { continuous }\end{array}$ & $\begin{array}{l}1.004 \\
(1.001- \\
1.007)\end{array}$ & 0.01 & $\begin{array}{l}1.005 \\
(1.002- \\
1.009)\end{array}$ & 0.0027 & $\begin{array}{l}1.006 \\
(1.001- \\
1.01)\end{array}$ & 0.02 & $\begin{array}{l}1.01 \\
(1.003- \\
1.016)\end{array}$ & 0.0034 \\
\hline \multicolumn{9}{|l|}{$\begin{array}{l}\text { CSF-CTCs - RPA } \\
\text { cutpoint }^{b}\end{array}$} \\
\hline$<x$ & Ref & & Ref & & Ref & & Ref & \\
\hline$\geq x$ & $\begin{array}{l}2.22(1.22- \\
4.03)\end{array}$ & 0.009 & $\begin{array}{l}2.84 \\
(1.45- \\
5.56)\end{array}$ & 0.0023 & $\begin{array}{l}5.38(1.27- \\
22.89)\end{array}$ & 0.02 & $\begin{array}{l}6.48 \\
(1.39- \\
30.25)\end{array}$ & 0.02 \\
\hline \multicolumn{9}{|l|}{ Cytology } \\
\hline Negative/atypical & Ref & & Ref & & Ref & & Ref & \\
\hline Positive/suspicious & $\begin{array}{l}1.67(0.91- \\
3.09)\end{array}$ & 0.1 & $\begin{array}{l}2.09 \\
(1.08- \\
4.05)\end{array}$ & 0.03 & $\begin{array}{l}4.36(1.03- \\
18.54)\end{array}$ & 0.046 & $\begin{array}{l}5.45 \\
(1.18- \\
25.30)\end{array}$ & 0.03 \\
\hline \multicolumn{9}{|c|}{$\begin{array}{l}\text { Cl: confidence interval, CSF: cerebrospinal fluid, CTC: circulating tumor cells, HR: hazard ratio, LM: leptomeningeal metastases, Ref: } \\
\text { reference, RPA: recursive partitioning analysis. }{ }^{a} \text { Adjusted for age at CSF collection, sex, number of brain metastases, and systemic } \\
\text { disease status. }{ }^{b} \text { Cutpoints, described as } \mathrm{x} \text { : overall LM cohort: }<61, \geq 61 \text {; lung cancer cohort: }<23, \geq 23 \text {. }\end{array}$} \\
\hline
\end{tabular}

\section{CSF Circulating Tumor Cells and Radiographic Burden of Disease}

Our three independent blinded neuroradiologists reviewed MRIs for a total of 99 out of the 101 patients from our prespecified cohort (two patients were excluded from neuroimaging analyses due to lack of MRIs performed within 30 days of CSF-CTC testing). To ensure the sample contained patients without LM-so performance of our blinded readers in identifying LM could truly be assessed-we also included MRIs for all patients with a recent ( $<6$ months) diagnosis of BrM who had an MRI of the brain performed within 30 days of CSF-CTC analysis. A total of 138/290 patients were reviewed, 99 with newly diagnosed LM and belonging to our prespecified cohort, plus 39 patients with BrM but no LM (Figure 1A); 115/138 had MRI of the spine available in addition to brain MRI. The independent readers were blinded to the underlying diagnosis of $\mathrm{LM}, \mathrm{BrM}$ or both. Within the 99 patients from our prespecified cohort, inter-rater agreement was only moderate for presence of LM in the brain (Kappa $=0.484,95 \% \mathrm{Cl}=0.358-0.614)$, substantial for BrM (Kappa = $0.798,95 \% \mathrm{Cl}=0.715-0.865)$, good for maximum diameter of $\mathrm{BrM}(\mathrm{ICC}=0.85,95 \% \mathrm{Cl}=0.778-0.905)$, and almost perfect for presence of LM in the spine (Kappa $=0.82,95 \% \mathrm{Cl}=0.705-0.897$ ); these results were similar for the overall group of 138 reviewed patients (not shown). When comparing to the official MRI report, there was total agreement between report and all three independent readers regarding presence or absence of LM in 47/99 patients (47\%), and between report and majority (2/3) of independent readers in 27/99 patients $(27 \%)$. However, in 25/99 patients (25\%) there was disagreement between the official report and the consensus from the independent readers, including 12 cases $(12 \%)$ for whom all three readers disagreed with the official report. Amongst these 12 cases, disagreement applied to brain MRI in 5 cases, spine MRI in 6 cases, and both brain and spine in 1 case. In the majority of these cases, a higher CSF-CTC count correlated with an agreement in presence of LM by our independent readers as opposed to in the official report: $10 / 12$ cases of disagreement were MRIs of the brain and/or spine that were reported as negative for LM in the official report but scored as positive by the independent readers, with a high CTC count (68-200) in 8/10 cases, and low CTC count (0-2) in only 2/10 cases; conversely, in the remaining 2/12 cases of disagreement, which were considered positive for LM in the official report but negative by our independent readers, the CTC count was 0 . Of note, diagnosis of LM for all our analysis was based on radiographic data from original MRI report, and not on data from blinded readers.

As expected, there was a statistically significant association between positivity of brain and spine MRI for LM and CSF-CTC count, with median CSF-CTC count being higher for patients whose MRI was considered positive by the consensus of our three independent readers (Table 3). When further dividing radiographic LM into linear and nodular patterns, there was a correlation with presence of either pattern of enhancement on brain MRIs and a higher CSF-CTC count; on the other hand, on MRIs of the spine only linear enhancement 
correlated with an increased CTC count, whereas there was no statistically significant difference in CSF-CTC count according to presence or absence of nodular enhancement. Presence of hydrocephalus was also associated with higher CSF-CTCs. There was no significant difference in CSF-CTC count according to number of BrM (divided into arbitrarily selected categories of no BrM, 1-5 BrM and $>5 \mathrm{BrM}$ ) or to maximum BrM diameter as a continuous variable (Supplementary table 3 ). In addition, there was no correlation between radiographic presence of LM and overall survival, including when evaluating each pattern of enhancement (linear vs nodular) separately (except for the small number of patients who had radiographic LM in their spine only, who had an increased risk of death compared to patients without radiographic LM; Table 3), or between number of BrM and survival. However, there was a significant difference in overall survival in patients with radiographic signs of hydrocephalus $(\mathrm{HR}=2.31,95 \% \mathrm{Cl}=1.34-3.97, \mathrm{p}=0.0025 ; \mathrm{Table} 3$ ), as well as a small, likely clinically irrelevant but statistically significant inverse association between maximum BrM diameter and outcome (HR = 0.95-0.96 depending on reader; Supplementary table 3 ). 
Table 3

Correlation between LM presence in MRI, CSF-CTC count and survival.

\begin{tabular}{|c|c|c|c|c|c|}
\hline MRI characteristic & Consensus interpretation ${ }^{a}$ & $\begin{array}{l}\text { Median CSF-CTC } \\
\text { count }\end{array}$ & $P$ value & $\begin{array}{l}\text { HR for OS } \\
(95 \% \mathrm{Cl})\end{array}$ & $\begin{array}{l}P \\
\text { value }\end{array}$ \\
\hline \multirow[t]{2}{*}{ LM in MRI brain } & Absent $(72 / 138,52 \%)$ & 1.5 & \multirow[t]{2}{*}{$<0.0001$} & Ref & \multirow[t]{2}{*}{0.88} \\
\hline & Present (66/138, 48\%) & 200 & & $\begin{array}{l}0.97(0.63- \\
1.50)\end{array}$ & \\
\hline \multirow[t]{2}{*}{ Linear enhancement in MRI brain } & Absent $(87 / 138,63 \%)$ & 3 & \multirow[t]{2}{*}{0.0003} & Ref & \multirow[t]{2}{*}{0.77} \\
\hline & Present (51/138, 37\%) & 200 & & $\begin{array}{l}1.07(0.68- \\
1.69)\end{array}$ & \\
\hline \multirow[t]{2}{*}{ Nodular enhancement in MRI brain } & Absent (102/138, 74\%) & 4 & \multirow[t]{2}{*}{0.0019} & Ref & \multirow[t]{2}{*}{0.73} \\
\hline & Present $(36 / 138,26 \%)$ & 200 & & $\begin{array}{l}1.09(0.67- \\
1.77)\end{array}$ & \\
\hline \multirow[t]{2}{*}{ LM in MRI spine } & Absent $(72 / 115,63 \%)$ & 4 & \multirow[t]{2}{*}{$<0.0001$} & Ref & \multirow[t]{2}{*}{0.34} \\
\hline & Present (43/115, 37\%) & 200 & & $\begin{array}{l}1.27(0.78- \\
2.09)\end{array}$ & \\
\hline \multirow[t]{2}{*}{ Linear enhancement in MRI spine } & Absent $(77 / 115,67 \%)$ & 4 & \multirow[t]{2}{*}{$<0.0001$} & Ref & \multirow[t]{2}{*}{0.16} \\
\hline & Present (38/115, 33\%) & 200 & & $\begin{array}{l}1.43(0.86- \\
2.35)\end{array}$ & \\
\hline \multirow[t]{2}{*}{ Nodular enhancement in MRI spine } & Absent $(98 / 115,85 \%)$ & 61 & \multirow[t]{2}{*}{0.45} & Ref & \multirow[t]{2}{*}{0.11} \\
\hline & Present $(17 / 115,15 \%)$ & 137 & & $\begin{array}{l}1.68(0.89- \\
3.17)\end{array}$ & \\
\hline \multirow[t]{4}{*}{ LM in MRI brain and spine } & Absent in both $(62 / 135,46 \%)$ & 1 & \multirow[t]{4}{*}{$<0.0001$} & Ref & \\
\hline & $\begin{array}{l}\text { Present in MRI brain only } \\
(31 / 135,23 \%)\end{array}$ & 64 & & $\begin{array}{l}1.10(0.63- \\
1.91)\end{array}$ & 0.74 \\
\hline & $\begin{array}{l}\text { Present in MRI spine only } \\
(9 / 135,7 \%)\end{array}$ & 200 & & $\begin{array}{l}3.84(1.67- \\
8.86)\end{array}$ & 0.0016 \\
\hline & Present in both $(33 / 135,22 \%)$ & 200 & & $\begin{array}{l}1.14(0.64- \\
2.02)\end{array}$ & 0.66 \\
\hline \multirow[t]{2}{*}{ Hydrocephalus } & Absent (116/138, 84\%) & 8 & \multirow[t]{2}{*}{0.0025} & Ref & \multirow[t]{2}{*}{0.0025} \\
\hline & Present $(22 / 138,16 \%)$ & 200 & & $\begin{array}{l}2.31(1.34- \\
3.97)\end{array}$ & \\
\hline \multirow{4}{*}{$\begin{array}{l}\text { Overall pattern of LM in MRI brain } \\
\text { and spine }\end{array}$} & Absent (48/111, 43\%) & 2 & \multirow[t]{4}{*}{0.0002} & Ref & \\
\hline & Linear only $(25 / 111,23 \%)$ & 200 & & $\begin{array}{l}1.32(0.70- \\
2.50)\end{array}$ & 0.39 \\
\hline & Nodular only $(9 / 111,8 \%)$ & 18 & & $\begin{array}{l}0.79(0.30- \\
2.06)\end{array}$ & 0.63 \\
\hline & $\begin{array}{l}\text { Both linear and nodular } \\
(29 / 111,26 \%)\end{array}$ & 200 & & $\begin{array}{l}1.43(0.78- \\
2.61)\end{array}$ & 0.25 \\
\hline $\begin{array}{l}\mathrm{Cl} \text { : confidence interval, CSF: cerebros } \\
\text { magnetic resonance imaging, OS: ov } \\
\text { brain and spine are smaller that the } \\
\text { few patients, which have been elimin }\end{array}$ & $\begin{array}{l}\text { nal fluid, CTC: circulating tumo } \\
\text { all survival, Ref: reference. }{ }^{\text {aDer }} \\
\text { al MRIs available due to lack o } \\
\text { ed from these analyses. }\end{array}$ & $\begin{array}{l}\text { S, HR: hazard ratic } \\
\text { nators in characte } \\
\text { ority consensus a }\end{array}$ & $\begin{array}{l}\text { 1: leptom } \\
\text { cs that a } \\
\text { igst our }\end{array}$ & $\begin{array}{l}\text { ningeal meta } \\
\text { a composite } \\
\text { dependent re }\end{array}$ & $\begin{array}{l}\text { es, MRI: } \\
\text { ARI } \\
\text { s for a }\end{array}$ \\
\hline
\end{tabular}

\section{Discussion}

Research on biomarkers for CNS metastases-including CTCs, circulating tumor DNA (ctDNA) and single cell analyses-has significantly advanced in recent years $[9,14,21,22]$, but their clinical significance is still unknown. This is the largest study describing 
CSF-CTCs as a quantitative biomarker predicting outcome in patients with LM from solid tumors in a clinical setting. Our study demonstrates a continuous relationship between CSF-CTC count and mortality, with an excess risk of $0.5 \%$ for each additional CSF-CTC for patients with newly diagnosed LM. For patients with lung cancer and newly diagnosed LM, CSF-CTCs were an even stronger predictor, with an excess risk of death of $1 \%$ with each additional CSF-CTC. This association between CSF-CTC count and outcome may facilitate a potentially expanded utility of CSF-CTCs as a quantitative biomarker of disease burden in the CNS compartment: not only as a diagnostic test, but also as a prognostic tool for newly diagnosed LM.

Previously, studies exploring the utility of CTC detection in CSF have centered in its performance as a diagnostic tool in LM. Aside from its improved sensitivity for LM diagnosis, CSF-CTC analysis offers a distinct advantage over CSF cytology and neuroaxis imaging: its results are quantitative, providing an objective scale that contrasts with the binary outcomes of CSF cytology and the lack of reproducibility of MRI measurements[7]. Our data show that presence of CSF-CTCs at or above the threshold of $61 \mathrm{CTCs} / 3 \mathrm{ml}$ in patients with newly diagnosed LM more than doubles the risk of death in this population over our follow-up period (median follow-up 3.9 months). This cutoff could potentially be used for stratification of patients at the time of LM diagnosis and before initiation of treatment, including clinical trials, which is particularly important in a disease where prognosis has been considered universally poor.

In addition, our results suggest the potential superiority of CSF-CTCs over neuroimaging as a marker of quantitative CNS disease burden in patients with LM. We found a statistically significant association between positivity of brain and spine MRI for LM and CSFCTC count, with median CSF-CTC count being higher for patients whose MRI was considered positive by the consensus of our three independent readers. This suggests there is a correlation between radiographic burden of disease in LM and CSF-CTC count, which in our data was maintained when analyzing nodular and linear enhancement in the brain, and linear enhancement on spine MRIs; nodular enhancement on spine MRIs was not associated with higher CSF-CTC count, perhaps due to the small number of patients (17/115). There was no association between any of these radiographic patterns of enhancement and overall survival in our sample, which is consistent with the findings of other studies [23]. Moreover, MRIs of the brain and spine are difficult to interpret at early stages of LM, and the currently used criteria by the RANO-LM group lack reproducibility[7]. Our results reflect this unreliability, with only moderate inter-rater agreement in determining presence of leptomeningeal enhancement in the brain, and better agreement on spine imaging. This underscores the challenges of interpreting MRIs in LM, even for neuroradiologists specializing in cancer imaging. For example, based on the combination of our independent assessments and official report, two patients from our newly diagnosed LM cohort would have been reclassified as not having LM, as their diagnosis was based exclusively on MRI findings (brain in one case and spine in the other) but all three independent readers considered their MRIs negative for LM. Both patients had negative cytology and no CSF-CTCs, highlighting that CSF-CTCs can provide a more objective measure of disease burden, and with a stronger correlation with survival than imaging.

With the expansion of liquid biopsies in recent years, enumeration of CTCs represents only one of the many analyses that can be performed in the CSF of patients with CNS metastases. In addition to being quantified, CSF-CTCs can also be isolated for genetic sequencing or even transcriptome analysis[21, 24-26], although currently these techniques are mostly relegated to the research setting and not routinely done in clinical practice. CtDNA can also be detected in the CSF of patients with both primary and metastatic brain tumors[27-29]; in patients with CNS metastases, ctDNA in CSF can contribute valuable information about the mutational profile in the CNS compartment, which may differ from the one in the primary tumor, potentially with therapeutic implications[27, 30]. The utility of CSF-CTCs and ctDNA as a method of liquid biopsy for patients with CNS metastases has not been directly compared, but these techniques likely provide complementary data.

LM are considered a separate biological entity from parenchymal BrM. Although the mechanisms of metastatic cell invasion of the CNS parenchyma are believed to be different from those of spread into the CSF[31-33], it has been recognized that one of the means of CSF dissemination leading to LM is through seeding from parenchymal lesions[34]. In fact, it is not uncommon in clinical practice for BrM and LM to coexist, as demonstrated in our sample, in which 71\% of patients with newly diagnosed LM had both LM and BrM. This includes a subset of 31 patients with newly diagnosed BrM who also had co-existing, newly diagnosed LM; in almost a third of these patients $(9 / 31,29 \%)$ the diagnosis of LM was exclusively based on a positive or suspicious CSF cytology, without evidence of LM on MRIs (Figure 1b). This highlights the importance of considering lumbar punctures in patients with BrM, in which CSF analysis may be the only way to diagnose LM at its early stages. Although LM and BrM are distinct clinicopathological entities in terms of their diagnosis, presentation, management, and prognosis, there is a degree of overlap between them that justifies exploring CSF-CTCs as a biomarker not only in LM, but potentially also in newly diagnosed BrM. As an example, among the 290 patients who had CSF-CTC analysis, there were 19 patients who had a CSF-CTC result above the threshold suggestive of LM diagnosis ( $\geq 3$ CSF-CTCs/3 ml)[14] but did not meet cytological and/or radiographic criteria for a diagnosis of LM. Of these, two patients likely truly had LM based on 
clinical criteria; of the remaining 17 patients, 12 had evidence of either dural (in one case) or superficial parenchymal brain metastases that could have conceivably shed malignant cells into the CSF, exemplifying how CSF-CTC quantification can be an indirect marker of disease burden in patients with BrM, even in the absence of overt LM.

A major strength of this study is the relatively large number of patients. Our study has several potential weaknesses, including its retrospective nature, which introduces the possibility of selection bias, as well as an element of variability in the timing of LM diagnosis across patients. Our initial overall sample of 290 patients was heterogeneous regarding time of LP in relation to patients' clinical course and LM diagnosis. We tried to mitigate this effect by selecting a more homogeneous subgroup of patients with LM diagnosed within a specific timeframe in relation to CSF-CTC collection, but within this group there are a variety of factors that could not be controlled for, such as prior treatments received. An additional source of heterogeneity, commonly seen in studies involving LM patients due to the rarity of the disease, is the mix of different histologies, which could limit generalizability of the results. Importantly, we were able to reproduce the results from the overall cohort of 101 patients with newly diagnosed LM in the subgroup with the most common histology (44 patients with lung cancer). While CSF-CTCs were not able to predict survival in patients with breast cancer, we attribute this result to the smaller number of patients with this diagnosis potentially rendering the trend towards a difference in survival statistically non-significant, which is illustrated by CSF cytology also being unable to predict survival in this patient group despite having being validated as a prognostic tool in patients with LM[23].

Our study also suffers from the drawbacks inherent to CTC testing using the CellSearch ${ }^{\circledR}$ platform-including the inability to capture melanoma cells, or epithelial cancer cells that have lost EpCAM expression, which may happen as the disease evolves and tumor cells transition into a mesenchymal phenotype[35]. However, the importance these EpCAM-negative CTCs may have in determining prognosis is unclear, as several studies analyzing CTCs from blood in patients with lung, breast and prostate cancer have found no correlation between CTCs discarded by the CellSearch ${ }^{\circledR}$ system and survival[36-38]. Lastly, another important limitation of our study is that we had access to a single CSF sample per patient, so the generalizability of our results to the dynamic changes of CSF-CTCs over time, although theoretically possible, is limited. Periodic analysis of CSF-CTCs in prospective trials could help establish this test as a marker of response to treatment or early recurrence, and a number of active clinical trials are now incorporating CSF-CTCs in their design[39].

In conclusion, our data shows that CSF-CTC analysis is a significant prognostic biomarker in patients with newly diagnosed LM, for whom it has a better correlation with outcome than both CSF cytology and MRI findings. Large prospective studies including patients with newly diagnosed BrM are needed to further define the utility of CSF-CTCs, ctDNA and other forms of liquid biopsy in the management of CNS metastases, with or without LM.

\title{
Declarations
}

Funding: This research was supported by grants from the Memorial Sloan Kettering Brain Tumor Center and the National Institutes of Health (P30-CA008748).

\section{Conflict of Interest:}

Financial: RJY has received institutional grant funding from Agios, and consulting fees from Agios, Puma, NordicNeuroLab and ICON plc, all unrelated to this work. The remaining authors declare no conflict of interest.

Non-financial: None.

Acknowledgements: Part of this study was presented at the Society of Neuro-Oncology Brain Metastases Conference in August 2020 and the Society of Neuro-Oncology Annual Meeting in November 2020.

Ethics Statement: This retrospective study was approved by the Memorial Sloan Kettering Cancer Center (MSKCC) Institutional Review Board. Institutional waiver of informed consent was obtained due to minimal patient risk associated with participation in the study.

\author{
Authorship: \\ Study design and data collection: MD, PS, IK, AS, AM, CT, RJY, EP \\ Statistical analysis and interpretation of the data: ASR, KSP, MD, PS, EP \\ Original draft preparation: MD, PS, EP
}

Page $10 / 14$ 
Critical revision of manuscript: MD, PS, IK, AS, ASR, KSP, LVR., AM, CT, RJY, EP

Data Availability Statement: Anonymized data will be shared by request from any qualified investigator.

\section{References}

1. Chamberlain MC (2010) Leptomeningeal metastasis. Curr Opin Oncol 22:627-635. doi:10.1097/CC0.0b013e32833de986

2. Le Rhun E, Taillibert S, Chamberlain MC (2013) Carcinomatous meningitis: Leptomeningeal metastases in solid tumors. Surg Neurol Int 4:S265-288. doi:10.4103/2152-7806.111304

3. Glitza IC, Smalley KSM, Brastianos PK, Davies MA, McCutcheon I, Liu JKC, Ahmed KA, Arrington JA, Evernden BR, Smalley I, Eroglu Z, Khushalani N, Margolin K, Kluger H, Atkins MB, Tawbi H, Boire A, Forsyth P (2020) Leptomeningeal disease in melanoma patients: An update to treatment, challenges, and future directions. Pigment Cell Melanoma Res 33:527-541. doi:10.1111/pcmr.12861

4. Devecka M, Duma MN, Wilkens JJ, Kampfer S, Borm KJ, Munch S, Straube C, Combs SE (2020) Craniospinal irradiation(CSI) in patients with leptomeningeal metastases: risk-benefit-profile and development of a prognostic score for decision making in the palliative setting. BMC Cancer 20:501. doi:10.1186/s12885-020-06984-1

5. Yang TJ, Wijetunga NA, Yamada J, Wolden S, Mehallow M, Goldman DA, Zhang Z, Young RJ, Kris MG, Yu HA, Seidman AD, Gavrilovic IT, Lin A, Santomasso B, Grommes C, Piotrowski AF, Schaff L, Stone JB, DeAngelis LM, Boire A, Pentsova E (2021) Clinical trial of proton craniospinal irradiation for leptomeningeal metastases. Neuro Oncol 23:134-143. doi:10.1093/neuonc/noaa152

6. Le Rhun E, Devos P, Boulanger T, Smits M, Brandsma D, Ruda R, Furtner J, Hempel JM, Postma TJ, Roth P, Snijders TJ, Winkler F, Winklhofer S, Castellano A, Hattingen E, Capellades J, Gorlia T, Van den Bent M, Wen PY, Bendszus M, Weller M (2019) European Organisation for R, Treatment of Cancer Brain Tumor Group Central Nervous System Metastases C, the EBTGIC The RANO Leptomeningeal Metastasis Group proposal to assess response to treatment: lack of feasibility and clinical utility and a revised proposal. Neuro Oncol 21: 648-658 doi:10.1093/neuonc/noz024

7. Patel AS, Allen JE, Dicker DT, Peters KL, Sheehan JM, Glantz MJ, El-Deiry WS (2011) Identification and enumeration of circulating tumor cells in the cerebrospinal fluid of breast cancer patients with central nervous system metastases. Oncotarget 2:752-760. doi:10.18632/oncotarget.336

8. Le Rhun E, Massin F, Tu Q, Bonneterre J, Bittencourt Mde C, Faure GC (2012) Development of a new method for identification and quantification in cerebrospinal fluid of malignant cells from breast carcinoma leptomeningeal metastasis. BMC Clin Pathol 12:21. doi:10.1186/1472-6890-12-21

9. Nayak L, Fleisher M, Gonzalez-Espinoza R, Lin O, Panageas K, Reiner A, Liu CM, Deangelis LM, Omuro A (2013) Rare cell capture technology for the diagnosis of leptomeningeal metastasis in solid tumors. Neurology 80: 1598-1605; discussion 1603 doi:10.1212/WNL.0b013e31828f183f

10. Lee JS, Melisko ME, Magbanua MJ, Kablanian AT, Scott JH, Rugo HS, Park JW (2015) Detection of cerebrospinal fluid tumor cells and its clinical relevance in leptomeningeal metastasis of breast cancer. Breast Cancer Res Treat 154:339-349. doi:10.1007/s10549-015-3610-1

11. Tu Q, Wu X, Le Rhun E, Blonski M, Wittwer B, Taillandier L, De Carvalho Bittencourt M, Faure GC (2015) CellSearch technology applied to the detection and quantification of tumor cells in CSF of patients with lung cancer leptomeningeal metastasis. Lung Cancer 90:352-357. doi:10.1016/j.lungcan.2015.09.008

12. Jiang BY, Li YS, Guo WB, Zhang XC, Chen ZH, Su J, Zhong WZ, Yang XN, Yang JJ, Shao Y, Huang B, Liu YH, Zhou Q, Tu HY, Chen HJ, Wang Z, Xu CR, Wang BC, Wu SY, Gao CY, Zhang X, Wu YL (2017) Detection of Driver and Resistance Mutations in Leptomeningeal Metastases of NSCLC by Next-Generation Sequencing of Cerebrospinal Fluid Circulating Tumor Cells. Clin Cancer Res 23:5480-5488. doi:10.1158/1078-0432.CCR-17-0047

13. Lin X, Fleisher M, Rosenblum M, Lin O, Boire A, Briggs S, Bensman Y, Hurtado B, Shagabayeva L, DeAngelis LM, Panageas KS, Omuro A, Pentsova El (2017) Cerebrospinal fluid circulating tumor cells: a novel tool to diagnose leptomeningeal metastases from epithelial tumors. Neuro Oncol 19:1248-1254. doi:10.1093/neuonc/nox066 
14. Cristofanilli M, Budd GT, Ellis MJ, Stopeck A, Matera J, Miller MC, Reuben JM, Doyle GV, Allard WJ, Terstappen LW, Hayes DF (2004) Circulating tumor cells, disease progression, and survival in metastatic breast cancer. N Engl J Med 351:781-791. doi:10.1056/NEJMoa040766

15. Liu MC, Shields PG, Warren RD, Cohen P, Wilkinson M, Ottaviano YL, Rao SB, Eng-Wong J, Seillier-Moiseiwitsch F, Noone AM, Isaacs C (2009) Circulating tumor cells: a useful predictor of treatment efficacy in metastatic breast cancer. J Clin Oncol 27:5153-5159. doi:10.1200/JC0.2008.20.6664

16. Allard WJ, Matera J, Miller MC, Repollet M, Connelly MC, Rao C, Tibbe AG, Uhr JW, Terstappen LW (2004) Tumor cells circulate in the peripheral blood of all major carcinomas but not in healthy subjects or patients with nonmalignant diseases. Clin Cancer Res 10:6897-6904. doi:10.1158/1078-0432.CCR-04-0378

17. Scher HI, Jia X, de Bono JS, Fleisher M, Pienta KJ, Raghavan D, Heller G (2009) Circulating tumour cells as prognostic markers in progressive, castration-resistant prostate cancer: a reanalysis of IMMC38 trial data. Lancet Oncol 10:233-239. doi:10.1016/S14702045(08)70340-1

18. Nevel KS, DiStefano N, Lin X, Skakodub A, Ogilvie SQ, Reiner AS, Pentsova E, Boire A (2020) A retrospective, quantitative assessment of disease burden in patients with leptomeningeal metastases from non-small-cell lung cancer. Neuro Oncol 22:675683. doi:10.1093/neuonc/noz208

19. Chamberlain M, Junck L, Brandsma D, Soffietti R, Ruda R, Raizer J, Boogerd W, Taillibert S, Groves MD, Le Rhun E, Walker J, van den Bent M, Wen PY, Jaeckle KA (2017) Leptomeningeal metastases: a RANO proposal for response criteria. Neuro Oncol 19:484-492. doi:10.1093/neuonc/now183

20. Magbanua MJ, Melisko M, Roy R, Sosa EV, Hauranieh L, Kablanian A, Eisenbud LE, Ryazantsev A, Au A, Scott JH, Park JW (2013) Molecular profiling of tumor cells in cerebrospinal fluid and matched primary tumors from metastatic breast cancer patients with leptomeningeal carcinomatosis. Cancer Res 73:7134-7143. doi:10.1158/0008-5472.CAN-13-2051

21. Chi Y, Remsik J, Kiseliovas V, Derderian C, Sener U, Alghader M, Saadeh F, Nikishina K, Bale T, lacobuzio-Donahue C, Thomas T, Pe'er D, Mazutis L, Boire A (2020) Cancer cells deploy lipocalin-2 to collect limiting iron in leptomeningeal metastasis. Science 369:276-282. doi:10.1126/science.aaz2193

22. Le Rhun E, Devos P, Weller J, Seystahl K, Mo F, Compter A, Berghoff AS, Jongen JLM, Wolpert F, Ruda R, Brandsma D, van den Bent M, Preusser M, Herrlinger U, Weller M (2021) Prognostic validation and clinical implications of the EANO ESMO classification of leptomeningeal metastasis from solid tumors. Neuro Oncol 23:1100-1112. doi:10.1093/neuonc/noaa298

23. Malani R, Fleisher M, Kumthekar P, Lin X, Omuro A, Groves MD, Lin NU, Melisko M, Lassman AB, Jeyapalan S, Seidman A, Skakodub A, Boire A, DeAngelis LM, Rosenblum M, Raizer J, Pentsova E (2020) Cerebrospinal fluid circulating tumor cells as a quantifiable measurement of leptomeningeal metastases in patients with HER2 positive cancer. J Neurooncol 148:599-606. doi:10.1007/s11060-020-03555-z

24. Li X, Zhang Y, Ding J, Wang M, Li N, Yang H, Wang K, Wang D, Lin PP, Li M, Zhao Z, Liu P (2018) Clinical significance of detecting CSF-derived tumor cells in breast cancer patients with leptomeningeal metastasis. Oncotarget 9:2705-2714. doi:10.18632/oncotarget.23597

25. Ruan H, Zhou Y, Shen J, Zhai Y, Xu Y, Pi L, Huang R, Chen K, Li X, Ma W, Wu Z, Deng X, Wang X, Zhang C, Guan M (2020) Circulating tumor cell characterization of lung cancer brain metastases in the cerebrospinal fluid through single-cell transcriptome analysis. Clin Transl Med 10:e246. doi:10.1002/ctm2.246

26. Pentsova El, Shah RH, Tang J, Boire A, You D, Briggs S, Omuro A, Lin X, Fleisher M, Grommes C, Panageas KS, Meng F, Selcuklu SD, Ogilvie S, Distefano N, Shagabayeva L, Rosenblum M, DeAngelis LM, Viale A, Mellinghoff IK, Berger MF (2016) Evaluating Cancer of the Central Nervous System Through Next-Generation Sequencing of Cerebrospinal Fluid. J Clin Oncol 34:2404-2415. doi:10.1200/JC0.2016.66.6487

27. Miller AM, Shah RH, Pentsova El, Pourmaleki M, Briggs S, Distefano N, Zheng Y, Skakodub A, Mehta SA, Campos C, Hsieh WY, Selcuklu SD, Ling L, Meng F, Jing X, Samoila A, Bale TA, Tsui DWY, Grommes C, Viale A, Souweidane MM, Tabar V, Brennan CW, Reiner AS, Rosenblum M, Panageas KS, DeAngelis LM, Young RJ, Berger MF, Mellinghoff IK (2019) Tracking tumour evolution in glioma through liquid biopsies of cerebrospinal fluid. Nature 565:654-658. doi:10.1038/s41586-019-0882-3

28. Wang Y, Springer S, Zhang M, McMahon KW, Kinde I, Dobbyn L, Ptak J, Brem H, Chaichana K, Gallia GL, Gokaslan ZL, Groves ML, Jallo GI, Lim M, Olivi A, Quinones-Hinojosa A, Rigamonti D, Riggins GJ, Sciubba DM, Weingart JD, Wolinsky JP, Ye X, Oba-Shinjo SM, Marie SK, Holdhoff M, Agrawal N, Diaz LA Jr, Papadopoulos N, Kinzler KW, Vogelstein B, Bettegowda C (2015) Detection of 
tumor-derived DNA in cerebrospinal fluid of patients with primary tumors of the brain and spinal cord. Proc Natl Acad Sci U S A 112:9704-9709. doi:10.1073/pnas.1511694112

29. Huang WT, Lu NM, Hsu WY, Chang SE, Atkins A, Mei R, Javey M (2018) CSF-ctDNA SMSEQ Analysis to Tailor the Treatment of a Patient with Brain Metastases: A Case Report. Case Rep Oncol 11:68-74. doi:10.1159/000486568

30. Boire A, Zou Y, Shieh J, Macalinao DG, Pentsova E, Massague J (2017) Complement Component 3 Adapts the Cerebrospinal Fluid for Leptomeningeal Metastasis. Cell 168: 1101-1113 e1113 doi:10.1016/j.cell.2017.02.025

31. Conrad C, Dorzweiler K, Miller MA, Lauffenburger DA, Strik H, Bartsch JW (2017) Profiling of metalloprotease activities in cerebrospinal fluids of patients with neoplastic meningitis. Fluids Barriers CNS 14:22. doi:10.1186/s12987-017-0070-5

32. Dankner M, Caron M, Al-Saadi T, Yu W, Ouellet V, Ezzeddine R, Maritan SM, Annis MG, Le PU, Nadaf J, Neubarth NS, Savage P, Zuo D, Couturier CP, Monlong J, Djambazian H, Altoukhi H, Bourque G, Ragoussis J, Diaz RJ, Park M, Guiot MC, Lam S, Petrecca K, Siegel PM (2021) Invasive growth associated with Cold-Inducible RNA-Binding Protein expression drives recurrence of surgically resected brain metastases. Neuro Oncol. doi:10.1093/neuonc/noab002

33. Boyle R, Thomas M, Adams JH (1980) Diffuse involvement of the leptomeninges by tumour-a clinical and pathological study of 63 cases. Postgrad Med J 56:149-158. doi:10.1136/pgmj.56.653.149

34. Hyun KA, Koo GB, Han H, Sohn J, Choi W, Kim SI, Jung HI, Kim YS (2016) Epithelial-to-mesenchymal transition leads to loss of EpCAM and different physical properties in circulating tumor cells from metastatic breast cancer. Oncotarget 7:24677-24687. doi:10.18632/oncotarget.8250

35. de Wit S, van Dalum G, Lenferink AT, Tibbe AG, Hiltermann TJ, Groen HJ, van Rijn CJ, Terstappen LW (2015) The detection of $\operatorname{EpCAM(+)~and~EpCAM(-)~circulating~tumor~cells.~Sci~Rep~5:12270.~doi:10.1038/srep12270~}$

36. de Wit S, Manicone M, Rossi E, Lampignano R, Yang L, Zill B, Rengel-Puertas A, Ouhlen M, Crespo M, Berghuis AMS, Andree KC, Vidotto R, Trapp EK, Tzschaschel M, Colomba E, Fowler G, Flohr P, Rescigno P, Fontes MS, Zamarchi R, Fehm T, Neubauer H, Rack B, Alunni-Fabbroni M, Farace F, De Bono J, MJ IJ, Terstappen L (2018) EpCAM(high) and EpCAM(low) circulating tumor cells in metastatic prostate and breast cancer patients. Oncotarget 9:35705-35716. doi:10.18632/oncotarget.26298

37. de Wit S, Rossi E, Weber S, Tamminga M, Manicone M, Swennenhuis JF, Groothuis-Oudshoorn CGM, Vidotto R, Facchinetti A, Zeune LL, Schuuring E, Zamarchi R, Hiltermann TJN, Speicher MR, Heitzer E, Terstappen L, Groen HJM (2019) Single tube liquid biopsy for advanced non-small cell lung cancer. Int J Cancer 144:3127-3137. doi:10.1002/ijc.32056

38. Boire A, Brandsma D, Brastianos PK, Le Rhun E, Ahluwalia M, Junck L, Glantz M, Groves MD, Lee EQ, Lin N, Raizer J, Ruda R, Weller M, Van den Bent MJ, Vogelbaum MA, Chang S, Wen PY, Soffietti R (2019) Liquid biopsy in central nervous system metastases: a RANO review and proposals for clinical applications. Neuro Oncol 21:571-584. doi:10.1093/neuonc/noz012

39. 39. Boire A, Brandsma D, Brastianos PK, Le Rhun E, Ahluwalia M, Junck L, Glantz M, Groves MD, Lee EQ, Lin N, Raizer J, Ruda R, Weller M, Van den Bent MJ, Vogelbaum MA, Chang S, Wen PY, Soffietti R (2019) Liquid biopsy in central nervous system metastases: a RANO review and proposals for clinical applications. Neuro Oncol 21: 571-584 doi:10.1093/neuonc/noz012

\section{Figures}

A)

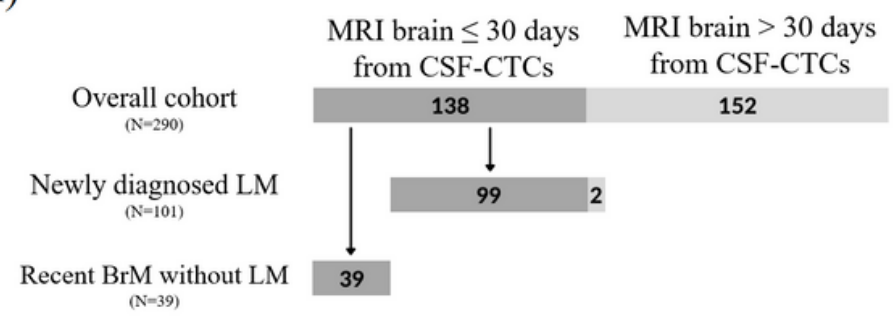

B)

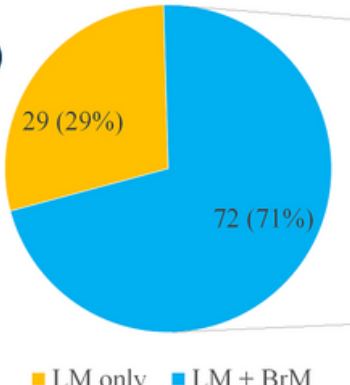

= LM only $=\mathrm{LM}+\mathrm{BrM}$
C)

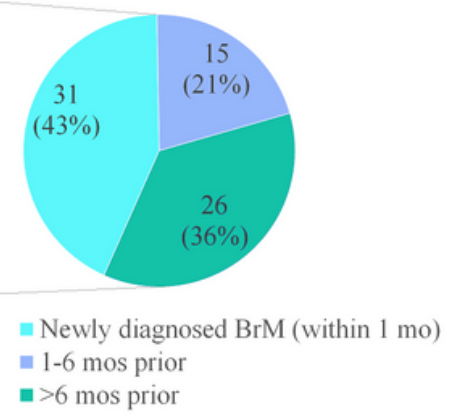

\section{Figure 1}


A) Flowchart detailing the 138 patients included in the study. B) Distribution of patients with LM only (29/101) vs both LM and BrM (72/101). C) Timing of BrM diagnosis in relation to LP for patients with concurrent LM and BrM (N=72).

A)
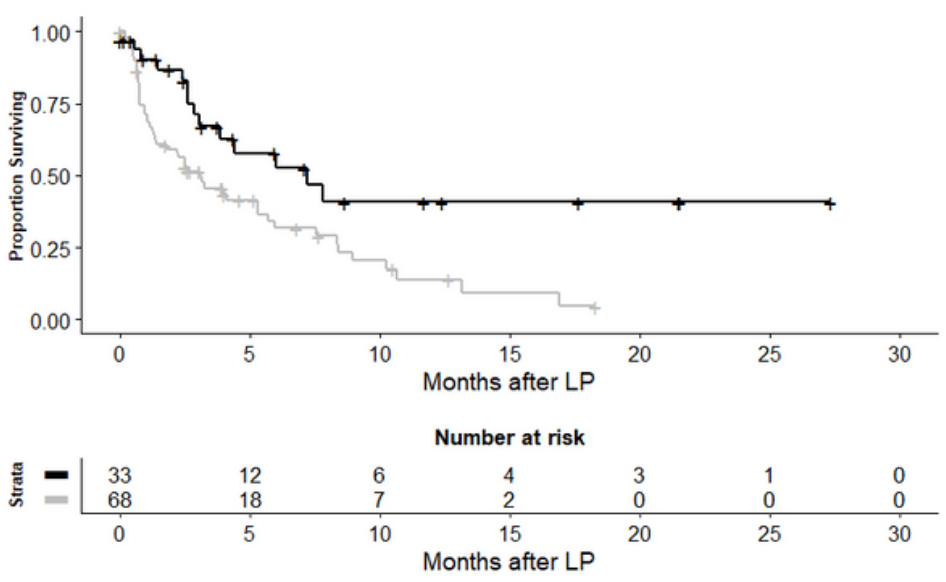

B)

+ CSF.CTCs $<23+$ CSF.CTCs $23+$
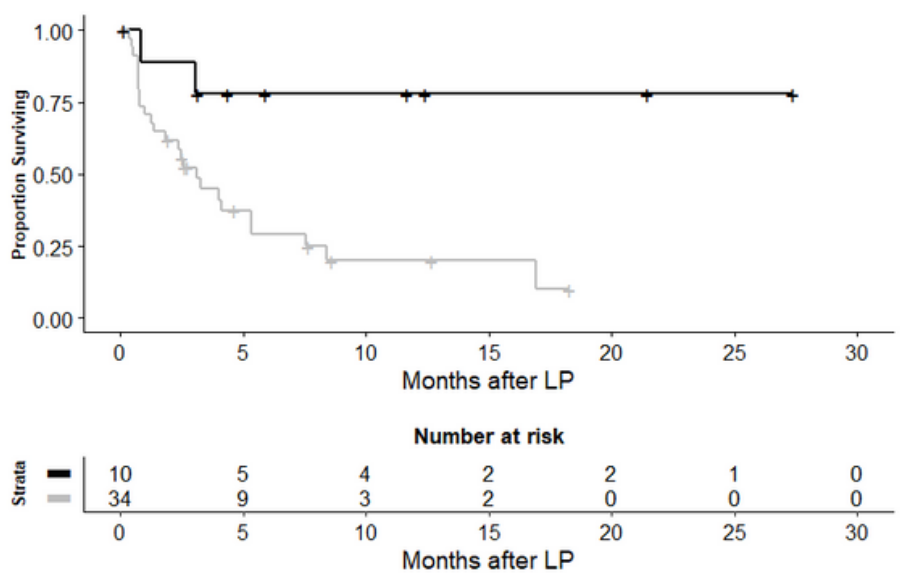

Figure 2

Survival curves according to optimal CSF-CTC cutoff determined by recursive partitioning analysis. A) All patients with newly diagnosed LM $(\mathrm{N}=101)$. B) Patients with newly diagnosed LM from lung cancer $(\mathrm{N}=44)$.

\section{Supplementary Files}

This is a list of supplementary files associated with this preprint. Click to download.

- Supplementarydata.docx 